then (in face of certain obvious difficulties) to declare that the work of art was something more than a "mirror" to the world, its function differing from that of diagrammatic or exact representation as an organism differs from a machine.

As a mode of distinction (and even of polemic) the point was a fair one, but it leaves us asking how far the image may legitimately be pursued. Certain German naturphilosophen took it, perhaps, to its logical conclusion by their implicit assumption that the systematized introspections and generalizations of philosophers concerning possible correspondences between the individual human organism and the external world might provide a scientifically verifiable account of natural phenomena. In practice, of course, such accounts were too far from the observable facts of nature to be of much permanent value-even Goethe's Metamorphosis of Plants, as Ritterbush points out, showing little concern for the material processes by which growth took place. At best, it might be said that their desire to find a view of nature that reconciles the human being to the universe is a permanent, if strictly subordinate, factor in much scientific research.

At a less ambitious level, the concept has been of value in both the arts and sciences. As one follows Ritterbush's account, however, certain ambiguities become discernible. "Organic form" can be of at least three types: it may be a relatively stable form, created by an organism and continuing to exist after that organism's death or withdrawal (the nautilus shell and the honeycomb provide obvious and classical examples); or it may be the form of a whole, living organism, caught at a single moment of its existence; or it may be the "total" form, in time and space, of an organism during a long period of development. Normally, I suppose, biologists aim to seize the form of an organism in this third sense (D'Arcy Thompson's remark, "Morphology is not only a study of material things and of the forms of material things, but has its dynamic aspect, under which we deal with the interpretation, in terms of force, of the operations of Energy" comes to mind) but it is noteworthy that the examples of scientific work on organic form given by Ritterbush tend to fall into the first and second categories.

This may simply be a reflexion of Ritterbush's special interest in the visual arts, of course; and no doubt the ambiguity I have mentioned raises few problems for practising biologists. When the concept of organic unity is transferred to art, on the other hand, the ambiguity becomes more crucial. A poem may be regarded as the isolable product of the poet; or it may be read in conjunction with a sense that it expresses the mind and experience of the poet and/or reader at a particular moment in time; or one may try to contemplate such interplay over a long period, in terms of "organic growth". For Professor Wimsatt there is no problem. With commonsense urbanity he cuts the knot, declaring roundly, "It is only to the finished product that we can apply the concept of organic unity." $\mathrm{He}$ also argues that to speak of a poem as an organism in any literal sense is absurd. What he works for, instead, is the doctrine of "an exceedingly subtle, intimate, manifold (and hence dramatic and imaginative) 'interinanimation' of parts in a poem." It is an attractive formula, but also a shade elusive, suggesting a desire to reap the rhetorical benefits of organic imagery without actual commitment to organic metaphor. One would like to see such potential objections more clearly faced.

Although Wimsatt's initial distinction makes his discussion more manageable, moreover, it also shuts off some of the more rewarding areas of the topic. Those critics who have found the concept most useful have always, I think, been interested in process as well as product. When they speak of a poem as having organic form they are making a comment not simply about the nature of the poem but about the nature of the poet in making it and the state of mind induced in the receptive reader. Wimsatt advances the (confessedly) "heretical" view that a good chess problem, "viewed according to the idealist organistic norm, has a more fully determined and hence more perfect structure than even a sonnet by Shakespeare." But this is precisely where the full organic metaphor might come to the critic's aid, suggesting the different sensory modes by which a poem communicates-bringing, as one might say (changing Coleridge's terminology slightly) "the whole psyche of man" into operation.

Coleridge, of course, is a crucial figure in the whole affair, for he was largely influential in introducing the concept to English readers. His contribution still tends to be underestimated, drawing partly as it did on an English tradition which differed in certain respects from that of the Germans. Both Ritterbush and Wimsatt, for example, cite Erasmus Darwin's whimsical Botanic Garden as an example of poetry which is, so to speak, "aware of the organic", but neither mentions his Zoönomia, a more intelligent and, I believe, a more seminal discussion. These matters are too intricate for a short review, however; it is enough to say that anyone who is interested in the topic as a whole, whether from the point of view of science or of the arts, will find much to quicken interest, and many references to follow, in this stimulating volume.

JOHN BEER

\section{Hungarian Research in Crop Production}

The First Twenty Years of Martonvasar. Edited by S. Rajki. Prepared for the press by G. Pal. Pp. $329+15$ plates. (Agricultural Research Institute of the Hungarian Academy of Science: Martonvasar, 1972.) \$16.00.

A SCIENTIFIC council set up by the Government in 1948 assessed existing facilities for research in Hungary and the need for new institutes. Plans were made for a plant production research institute at Martonvasar to combine practical and theoretical work on genetics, plant breeding, physiology and seed production. The institute began with two workers in 1949 , had 19 a year later and now has about 40 scientists. The main developments in the programme were in the 1950 s when a large experimental farm was also acquired. Martonvasar, along with other agricultural research institutes, was placed under the Hungarian Academy of Sciences. Successes in the 1950s included the adaptation and development of American methods for producing hybrid maize seed and the selection of new varieties of wheat. The institute claims an important share in the improvement of the yields of Hungary's two main crops--wheat and maize; yields of both have practically doubled since the end of the war, recent peak averages have been $27 q$ /ha of wheat and $38 \mathrm{q} /$ ha of maize.

This book has 3 texts-in English, Hungarian and Russian. The director (Dr. Sandor Rajki) described the development of the institute and its experimental farm; publications by members of the staff are listed. Present work is described in separate chapters on: Plant Physiology and Biochemistry (L. Gaspar); Plant Genetics (S. Rajki); Plant Breeding (I. Kovacs) and Plant Production (B. Gyorffy). The book will be valuable to those interested in the development of agricultural research in Hungary since 1950 , to plant breeders, and, obviously, to scientists who may plan to visit Hungary. The account (by A. Kuti) of the institute's experimental farm (of 572 ha) is an interesting example of the practice and economics of a large farming unit.

G. W. Cooke

\section{Experiments on Stress}

Urban Stress: Experiments on Noise and Social Stressors. By David C. Glass and Jerome E. Singer. Pp. xiii + 182. (Academic: New York and London, March 1972.) $\$ 8.75$.

THIS book has a most inappropriate title. One might expect it to cover a variety of the conditions met in modern 